\title{
Determinants of Cashew Nut Exports of Guinea-Bissau
}

\author{
Júlio Vicente Cateia ${ }^{1}$, Clailton Ataídes de Freitas ${ }^{2} \&$ Paulo Ricardo Feistel $^{2}$ \\ ${ }^{1} \mathrm{PhD}$, Universidade Federal do Parana, Curitiba, Brazil \\ ${ }^{2}$ Graduate Program in Economics and Development. Departments of Economics, Universidade Federal de Santa \\ Maria, Santa Maria, Brazil \\ Correspondence: Júlio Vicente Cateia, 2335 Rue des Meuniers, Quebec, QC., G2C 1R2, Canada. Tel: \\ 1-819-580-8745. E-mail: juliocateia@yahoo.com.br
}

Received: June 6, 2021

Accepted: August 9, 2021

Online Published: August 15, 2021

doi:10.5539/ijef.v13n9p117

URL: https://doi.org/10.5539/ijef.v13n9p117

\begin{abstract}
This study examines the impacts of income, exchange rate, and conflicts on Cashew nuts exports of Guinea-Bissau. The main results obtained by analyzing the impulse response function and variance decomposition showed that, in the short term, exchange rates shocks don't explain the external demand for this commodity. External demand for cashew nuts responds to changes in global income and Civil Conflicts. However, in the long run, these variables have no impact on cashew nuts exports.
\end{abstract}

Keywords: foreign demand, cashew Nuts, Guinea-Bissau economy

JEL: F1; F14; Q17.

\section{Introduction}

The world demand for agricultural commodities has increased significantly in the last four decades (UNCTAD, 2012), making it a feasible option for countries in transition to integrate the world economy via international trade. This trade expansion is explained by the extraordinary increase in international commodity prices never seen since 1970. According to UNCTAD (2012), in 2003 and 2011, the boom not only broadly affected all commodity categories but was also the main historically registered by that institution.

Specifically, in Guinea-Bissau, from 1990 to 2011, exports of agricultural products grew at rates above $60 \%$. The representation of the Guinean agrarian sector in the early 1990 s rose from $80.12 \%$ to $90.91 \%$ in 2011 (Faostat, 2015). This percentage makes the country first among those with the largest share of agricultural products in the export grid. This increased participation of the farming sector in the total exported is explained by cashew nut exports, which grew by about 75\% (Faostat, 2015). Since 2000, this product has been responsible for more than $70 \%$ of Guinea-Bissau's exports destined for India, its leading trading partner.

The growing external demand for cashew nuts increasingly drives the cashew nut sector and consequently the Guinean economy. In 1995, the areas destined for cashew plantation were about 103 thousand hectares (Government official reports of Guinea-Bissau, henceforth Guinea-Bissau, 2010).

Guinea-Bissau is currently one of the world's leading cashew nut producers. In 2012, the latest information found, the country produced USD 113,970 million, behind Vietnam (USD 1,042,410), Nigeria (USD 732,199), India (USD 595,212), Ivory Coast (US\$393,890), Benin (US D488,803) and Philippines (USD 116,014). On a global scale, the country is an important player in the market, often favored by the quality of the nut produced and weather conditions.

As a result, the Guinean government has been adopting policies to promote the export of this commodity since customs revenues contribute to the country's development policies. The customs revenue from nut exports contributes between $35 \%$ and $40 \%$ of the total tax revenue generated since 2007 , and the tax on cashew nut exports was about USD 40 million (Guinea-Bissau, 2010).

It is essential to highlight that, historically, the production and marketing of traditional agricultural export products, in most African countries, in Guinea-Bissau is no different, are controlled by the Government (Diao, Dorosh, \& Rahmn, 2007). This state interference in the agricultural sector has two purposes, namely: to maintain the fiscal balance of the public accounts, through the revenue generated by export taxes, and to ensure, through the agricultural policy, the growth and agriculture modernization, so that this sector maintains its participation in 
the GDP. The purpose is to promote GDP growth, employment, and resources for poverty reduction programs. In Guinea-Bissau, the share of the agricultural sector in GDP is approximately $54 \%$, while de share of service and manufacturing sectors is about $11 \%$ and $35 \%$, respectively.

However, the government's action in the sector was abruptly interrupted by the Civil conflict of 1998, a type of conflict that can have different effects on an economy. Imai and Weinstein (2000) argue that the Civil War can produce distortions in markets, high inflation, and large budget deficits. The Civil conflict has impacted productive activities and reduced by about $34 \%$ the share of the agricultural sector on GDP (WB development indicators, 2014).

Given the importance of cashew nut for the Guinean economy, described briefly above, this research seeks to understand how the demand for cashew nut exports from Guinea-Bissau reacts to shocks in the world income, exchange rate, external and internal prices. These variables appear recurrently in the literature in studies of export demand, as discussed below. Additionally, we verify whether the Civil War of 1998 caused a structural change in Guinean cashew nut exports.

Thus, understanding how the country's exports react to shocks in the variables analyzed in studies of international trade flows can serve, especially to guide the Government in preparing more consistent economic policies precisely in those sectors that have comparative advantages. Via (2011) argues that knowing the trade magnitude elasticity may allow policymakers to deal with the inevitable, or even predictable, changes in the trade equilibrium, income, and the employment level, especially in countries with an export basket concentrated in few agricultural products like Guinea-Bissau.

Previous studies on export demand, as detailed in Section 2, don't focus on specific products. However, it is known that the commodities share in the export grid is different. Past studies that evaluate the export determinants at the sectoral level are carried out either in developed economies or in counties with some diversification in the productive structure. Furthermore, in many cases, previous works estimate the reaction of external demand to single-variable shocks. Thus, this study advances in several directions. First, we consider the existence of heterogeneities in the sectors and model the reaction of exports to external demand shocks. Second, to the best of our knowledge, this study is the first to analyze the impacts of the Civil conflict on cashew nut exports.

The research questions are: how does the demand for Guinean cashew nut exports react to shocks in external and internal prices, world income, and the exchange rate between 1990 and 2011? Did the 1998 Civil War cause a structural change in export demand from Guinea-Bissau? We aim to portray the importance of cashew nut exports to the Guinean economy, from 1990 onwards; estimate, via an autoregressive vector (VAR) model, the reaction of demand for cashew nut exports to shocks in world income and the exchange rate between 1990 to 2011; and verify whether the civil conflict in Guinea- Bissau in 1998 changed the pattern of cashew nut exports.

As hypotheses, it assumed that: the demand for Guinean cashew nut exports, from 1990 to 2011, is not influenced by the external and internal prices of this commodity, by the exchange rate, and by the world income. The political instability that occurred in Guinea-Bissau in June 1998 did not impact the demand for cashew nuts.

economy. They applied both the Vector cointegration model and the GARCH model. This study did not find any causal relationship between exchange rate volatility and export performance. The remainder of this study is structured as follows: Section 2 makes a historical incursion into the literature. Section 3 presents the econometric model and data. In Section 4 analyzes the results. Section discusses the results. Section 6 Concludes.

\section{Demand for Exports: Related Literature}

There is growing literature on export demand. Most of these publications investigate the determinants of demand by estimating the elasticity of demand to the selected variables, such as income and exchange rate. The seminal work by Orcutt (1950) has been pointed out as the first that estimated the external demand for exports. He found that, in the absence of retaliatory measures, exchange devaluation impacted the trade balance and, therefore, on external demand.

Goldstein and Khan (1987) investigated through the simultaneous approach the price response to shocks in demand and supply for aggregate exports of industries in eight countries in the period 1955-1970. The authors find a high price elasticity in demand for exports, which is even greater than that obtained by previous surveys.

Cavalcanti and Ribeiro (1998) analyzed the performance and determinants of Brazilian exports in the 1977/96 period by estimating the international trade equations for essential products and manufactured products (monthly data). For the former, they pointed out that relative prices were the main determinants of Brazilian exports. For 
the latter, they found an exogenous growth trend, although not explicitly identified, that can be related to the growth of internal productive capacity or the evolution of external demand.

Recently, export demand has been the object of empirical analysis also applied to bilateral trade. Haider, Afzal, and Riaz (2011) evaluated Pakistan's bilateral trade in 1973-2008, based on the elasticity functions of imports and exports in that country. The results of the estimates showed that income was the primary determinant of demand for exports and imports. The exchange rate and income were important in determining the trade flow between Pakistan and its trading partners.

Export demand from a specific sector has also been the object of empirical investigation (Reimer, Zheng, \& Gehlhar, 2012). The authors estimated the elasticity of export demand for US corn, soybeans, and wheat. They found that there was a high elasticity of demand for exports of these products. This result is statistically significant at the conventional level.

Pandey (2013) empirically examined the Marshall-Lerner condition for India, estimating equilibrium export and import elasticities using a multivariate cointegration approach. The main result achieved by this study is that the demand for exports responded positively to the variation in world income.

Monte (2012) analyzed the impacts of shocks on external and internal prices, external and internal incomes, and the exchange rate on coffee exports from Espírito Santo (a Brazilian state), using the VAR methodology. The study found that coffee exports reacted more to exchange rate shocks. Exporters took more time to respond to shocks in external and internal prices and external and internal income.

Silva and Bacchi (2005) used the VAR methodology to estimate the equations that explain the main conditions of international trade in Brazilian raw sugar, based on the supply and demand curves. By adopting this procedure, the authors concluded that only foreign income, the exchange rate, and the foreign price influenced the foreign trade of sugar. The foreign price was not statistically significant in the short run.

There is a growing literature that uses the error correction model (VECM) or the vector autoregressive model (VAR), as these models facilitate the long-term analysis of the relationship between the variables. For instance, Aydin Çiplak and Yücel (2004) estimated the demand for exports and imports for the Turkish economy from 1987 to 2004, using both the single-equation model and the VAR model. The authors pointed out that exchange rate and income shocks were the primary determinants of the trade deficit, but not of the variation in export demand.

Gbadebo (2006) analyzes the trade on African agricultural commodities to the United States from 1981 to 2004 (annual data), using the VAR modeling. The author finds that the demand for exports of these commodities was positively related to variations in income in the United States. There was price inelasticity in this country's demand concerning exports from Sub-Saharan African countries.

Boug and Fagereng (2007) examined the exchange rate volatility and trade performance of the Norwegian economy. They applied both the Vector cointegration model and the GARCH model. This study did not find any causal relationship between exchange rate volatility and export performance.

\section{Method}

This section is intended to present the proposed model for estimating the export demand for cashew nuts from Guinea-Bissau and the econometric procedures

\subsection{The Vector Autoregressive (VAR) Model}

VAR models were introduced in empirical studies of economics by Sims (1980) to critique traditional simultaneous equation models. According to Watson (1994), the VAR model provides a flexible and treatable framework for economic time series analysis since macroeconomic variables are generally dynamic, with interrelated fluctuations cycles. In the present case, demand for cashew nut exports is affected by past and contemporary shocks of the exchange rate, world income, cashew nut prices, etc.

Thus, considering a structural $\operatorname{var}(\mathrm{p})$ of order $\mathrm{p}$ :

$$
A X t=B o+B 1 X t-1+\ldots+B i X t-i+B \varepsilon t
$$

where $X t=(X 1 t, \ldots, X i t)$ is a vector with the endogenous variables, namely: $X D$ cashew nuts exports; $P G B$ domestic cashew nuts price; $P M$ external cashew nuts price; $C A M B$ exchange rate, US dollar/Franc CFA; $Y M$ world income; Bo is a vector of $n \times 1$ constants; Bi denotes a nxn matrix of coefficients; B is a $n \times n$ diagonal matrix of standard deviations; and $\varepsilon t=(\varepsilon 1 t, \ldots, \varepsilon t)$ is a vector of $\mathrm{nx} 1$ dimension of the independent and identically distributed random errors with zero mean and constant variance, i.e., $\varepsilon t \sim$ i.i.d $(0, \underline{U})$, where $U$ 
is a positive defined matrix that contains structures of variance and covariance.

The VAR model, therefore, admits the existence of the feedback effects. In other words, each variable affects and is affected by others by contemporaneously and lagged values (Hamilton, 1994). The problem with variables being endogenously defined is that they will be correlated with the error term. However, appropriate techniques and tools minimize this type of problem.

Thus, by rewriting Equation (1) in reduced form, we have:

$$
X t=\varphi 0+\varphi 1 X t-1+e t
$$

where $\varphi_{0}$ is an inverse matrix "A" multiplied by the vector of constants; and $\varphi_{1}$ is the matrix of coefficients.

To specify the model or choose the lag order of the stochastic processes, we use the traditional model selection criteria, such as AIC, BIC, and HQ. Then, we verify if the estimated residuals are white noise processes using the Ljung-Box test ( $Q$ test). It is worth noting that stationarity is a necessary condition to estimate time series. According to Morettin and Toloi (1985, p. 24), a time series is stationary if its first two moments (average and variance) are constant, while the covariance depends only on the time lag and not on the entire period. In the practical terms, as stated in Bueno (2008), the KPSS (Kwiatkowski, Phillips, Schmidt, and Shin), Dickey and Fuller Augmented (ADF), and PP (Phillips and Perron) tests are used to verify if the model time series are stationary. However, due to low test power in ADF and PP statistics, the KPSS test is increasingly preferred in the literature. For this reason, we only apply the former test.

Based on the results of the estimates of the VAR model, it is possible to generate the impulse response function and the decomposition of the variances of the studied times series. The term impulse deals with disturbances that can affect the behavior of variables (response) over time. Therefore, long-term variations of these variables may result from their reactions to the shocks caused - impulse response. When processes are stationary, consequently stable, surprises (unexpected shocks) tend to dissipate over time. But when they are not stationary, there is an unstable trajectory in the behavior of the times series, signaled by explosive variances. Additionally, the model can also be examined using variance decomposition. This procedure makes it possible to observe the percentage of the forecast error variance arising from each endogenous variable over the forecast horizon. This study also performs this analysis.

Meanwhile, structural break analysis can be performed using the Chow test. For Enders (2010, p. 104), the Chow test can be used when abrupt changes in a particular date are suspected. The test allows us to compare regressions before and after the event. If the two results are not statistically different, we don't reject the null hypothesis that there was no structural change in the data generating process.

\subsection{Data and Sources}

The cashew nuts exports and the respective external and internal prices are from the Food and Agriculture Organization of the United Nations (FAOSTAT). The exchange rate data are from the Central Bank of West African States (BCEAO) and express the US dollar/CFA Franc (Guinea-Bissau currency) ratio. For the world income variable, we calculate the share of the income of Guinea-Bissau's main trade partners in the GDP as follows:

$$
Y M=\alpha_{1} P I B_{I N D I A}+\alpha_{2} P I B_{\text {SINGPURA }}
$$

where the share values $\alpha_{1}$ and $\alpha_{2}$ represent percentages of cashew nuts destined to India and Singapore respectively. GDP data of India and Singapore are from the World Bank Development Indicators. The variables are expressed in millions of US dollars (biannual).

\section{Results}

This section presents the estimates of the VAR model, interprets the results obtained with the impulse-response function and the decomposition of the forecast error variance.

\subsection{Preliminary Tests in VAR Modeling}

As shown in Table 1, not all times series offer the same behavior over time. Some are level-integrated, i.e, I $(0)$, but the others are first-difference-integrated, i.e., I(1). The XD and PM variables are both $\mathrm{I}(0)$ because the calculated statistics of the KPSS tests, 0.193 and 0.086 , respectively, are lower than the critical statistics at the significance level of $5 \%(0.465)$, which leads to non-rejection of the null hypothesis (stationary times series). However, PGB and CAMB are stationary in first differences, considering a significance level of up to $10 \%$, since the statistics calculated for the KPSS tests $(-0.044$ and 0.285 , respectively) are lower than the critical statistic (0.349). The YM variable is considered stationary in first differences at the $1 \%$ significance level. Therefore, the PGB, CAMB, and YM time series are I(1). 
Table 1. Unit root test results

\begin{tabular}{ccc}
\hline Variable & Level series & Series in first differences \\
\hline XD & KPSS & KPSS \\
PGB & $0,193(0,465) \dagger$ & - \\
PM & $0,567(0,465)$ & $-0,044(0,349) \dagger$ \\
CAMB & $0,086(0,465) \dagger$ & - \\
YM & $0,983(0,465)$ & $0,285(0,349) \dagger$ \\
\hline
\end{tabular}

Source: Own elaboration. $\dagger$ Rejection at the $5 \%$ significance level.

Note. () critical test statistics values.

Once the unit root test is performed, sequential tests are applied to define the lag order $\mathbf{p}$ of the VAR model. For this, we set Pmáx equals 3. Through the information criteria AIC, BIC, and HQC, we observe that it is a VAR (1) since the calculated statistics of these tests were significant in the first lag (Table 2).

Table 2. Selection of VAR order

\begin{tabular}{|c|c|c|c|c|c|}
\hline Lag & $\log . \mathrm{L}$ & $\mathrm{p}(\mathrm{LR})$ & AIC & BIC & HQC \\
\hline 1 & $-1373,513$ & & $21,929^{*}$ & $22,598^{*}$ & $22,201 *$ \\
\hline 2 & $-1370,856$ & 0,999 & 22,279 & 23,504 & 22,776 \\
\hline 3 & $-1367,158$ & 0,999 & 22,611 & 24,394 & 23,336 \\
\hline
\end{tabular}

Source: Own elaboration.

Note. \# is the degree of lag of the VAR system. The maximum degree of lag is $3 . *$ indicates the best lag for the VAR.

The previous two steps are required to specify the VAR model order. The VAR (1) model was defined as a candidate. According to Table 3, for $X D$, the null hypothesis (white noise) is not rejected considering a significance level of $5 \%$, since the statistic was calculated for the Ljung-Box test (0.002) is lower than the critical statistics (18.5). For the reported values of the $Y M$, the calculated statistic is also lower than the critical statistic for the Ljung-Box test, 0.0160 and 18.5, respectively. In this sense, the null hypothesis was not rejected, and, therefore, it was inferred that the residuals are not autocorrelated. The same applies for other variables. By the autoregressive conditional heteroskedasticity $(\mathrm{ARCH})$, the null hypothesis is not rejected at $10 \%$ since the p-value is high, signaling a low probability of error type I, i.e., rejecting H0 when it is true (Table 3).

Table 3. Ljung-Box test

\begin{tabular}{lll}
\hline Variable & Ljung-BOX & $p$-valor \\
\hline XD & $0,002(18,5) \dagger$ & 0,860 \\
PGB & $0,014(18,5) \dagger$ & 0,913 \\
PM & $0,430(18,5) \dagger$ & 0,800 \\
CAMB & $4,98185 \mathrm{e}-005(18,5) \dagger$ & 0,886 \\
YM & $0,0160(18,5) \dagger$ & 0,446 \\
\hline
\end{tabular}

Source: Own elaboration.

Note. () critical values for the Ljung-Box test. $\dagger$ Rejection at the $5 \%$ significance level.

Therefore, the VAR (1) model is a best-fit model. The following subsection presents and interprets the estimated coefficients of this model. The variables of the present VAR model are estimated in level. Sims, Stock, and Watson (1990) argue that stationary and non-stationary series can be mixed since the VAR model is developed to analyze the inter-relationships between variables.

\subsection{Estimation and Interpretation of the VAR Model}

Estimating the VAR(1) model in reduced form yields the coefficients of contemporaneous relations presented in Table 4. The values of the model equations are represented in rows. In each row or column, the values outside parentheses are the coefficients or estimates of the model parameters, whereas the values in parentheses are the respective standard errors.

Estimating the VAR(1) model in reduced form yields the estimates of the coefficients of contemporaneous relations presented in Table 4. The values of the model equations are represented in lines. In each row and 
column, the values outside parentheses are the coefficients or estimates of the model parameters and the values in parentheses are the respective standard errors. Eac variable in column influences variables in rows.

Table 4. Results of VAR(1) model estimates

\begin{tabular}{ccccccc}
\hline Variable & $X D_{t-1}$ & $P G B_{t-1}$ & $P M_{t-1}$ & $C A M B_{t-1}$ & $Y M_{t-1}$ & Dummy* \\
\hline$X D_{t}$ & $0.925(0.044) \dagger$ & $0.054(0.112)$ & $0.598(0.308) \dagger$ & $0.191(0.893)$ & $0.465(0.171) \dagger$ & $--0.855(0.499) \dagger$ \\
$P B G_{t}$ & $0.050(0.035)$ & $0.041(0.090)$ & $0.550(0.249) \dagger$ & $0.164(0.721)$ & $0.071(1.025)$ & \\
$P M_{t}$ & $0.005(0.007)$ & $0.00(0.018)$ & $0.845(0.05) \dagger$ & $0.020(0.145)$ & $-0.02(0.206)$ & \\
$C A M B_{t}$ & $-0.001(0.04)$ & $-0.00(0.011)$ & $0.016(0.031)$ & $-0.04(0.090)$ & $-0.02(0.128)$ & \\
$Y M_{t}$ & $0.002(0.003)$ & $0.002(0.008)$ & $-0,029(0,022)$ & $0.006(0.064)$ & $-0.08(0.091)$ & \\
\hline
\end{tabular}

Source: Own elaboration.

$\dagger$ Significant at the 5\% significance level.

*intercept.

As the main interest is on the response of the XD variable to shocks in the other model variables, we focus on interpreting this variable. That said, observe that the signs of the coefficients of the PGB are not as expected and are not statistically significant, considering a significance level of $5 \%$. In other words, domestic cashew nut prices shocks do not influence the trajectory of external demand for Guinean cashew nuts. Likewise, the coefficients of the CAMB are not significant at 5\%, also indicating that foreign demand for Guinean cashew nuts does not respond to exchange rate shocks.

First, there are instabilities in the model's parameters, signaling an impact of the Civil Conflict on the data generating process. This situation is confirmed by applying the Chow test to assess the structural break in external demand for cashew nuts. The calculated Chow test statistic is $\mathrm{F}_{5,32}=5.78$, which is statistically significant at $1 \%$ suggesting that Civil Conflict has affected Guinea-Bissau's cashew nut exports.

The PM presents statistically significant coefficients, at a 5\% level, suggesting that a variation in the international price tends to cause changes in the demand for cashew nut exports. A $1 \%$ variation in the external price causes a contemporary variation of about 0.60 percentage points in cashew exports. This relationship has been verified since the beginning of the decade when the quantum of exported cashew nuts began to follow the growing trends in its external price. For example, the 36.15\% growth in cashew nut exports between 1990 and 2000 is also explained by the favorable external price of this commodity, which increased by about $9 \%$.

Similarly, the YM estimates were significant, considering a significance level of 5\%, which indicates that a $1 \%$ increase in foreign income tends to provoke an increase of 0.45 percentage points in cashew exports. When analyzing current exports concerning their flow in the immediately previous period, we find this variable has a statistically significant coefficient, at $5 \%$, indicating stability in the behavior of Guinean exports. In other words, a $1 \%$ increase in external demand in the previous period rises by about 0.9 percentage points the current flow of exports.

The model's estimates also showed a dynamic relationship between the domestic cashew nut price in the current period and the external cashew price in the previous period. This relationship is significant since a $1 \%$ increase in the external price in the last period causes a recent change of 0.55 percentage points in the domestic price of cashew nuts. This relationship can be analyzed considering the efficiency of the international cashew nut market. The significance of the coefficient suggests that the cashew nut market is integrated, and information flows between the leading producers, signaling that the Single Price Law (SPL) may be valid when analyzing the dynamics of price formation in this market in each period.

In addition, the external price of the previous period influences the current external price. The slow price adjustment can result from several factors: (i) supply shocks may take time to affect the product market; (ii) the signals emitted by the market are not instantly perceived, that is, agents take time to adjust prices because the information is not fully accessible or is slowly perceived and (iii) after the sales or purchase contracts are signed, their revision may involve high costs that are not economically negligible. Thus, although not all variables that influence Guinea's foreign trade have statistically significant coefficients, in general, the estimates of the proposed model are robust since all external variables influenced the behavior of the demand for exports. A comparative analysis with the revised literature is required. However, studies reviewed in Section 2 did not focus on a specific product. The studies that aimed to assess the behavior of exports of a particular product were carried out either at state levels within a country or in countries with characteristics different from those observed in Guinea-Bissau, making such comparison so tricky. 


\subsection{Impulse-Response Function and Variance Decomposition Fidelity}

To capture the reaction of vectors to shocks of one standard deviation in another vector, we generate the graphs of the impulse-response function, which are depicted in Figure 1. These shocks can come from changes in the external situation or the internal condition. The impulse-response functions, Figure 1, comprise a forecast period of twelve semesters. What stands out, in general, is the impacts of the shocks through four semesters. The first Figure (a) shows that shocks in the external demand variable had negative effects in the first semester. However, these effects quickly dissipated over time, as, from the second half of the year onwards, the processes resumed their long-term trajectories.

It is possible to observe that the shocks in the domestic price of cashew nut (PGB) - Figure (b) in Table 1 caused adverse effects on the external demand in the first semester. This impact is expected since Guinea-Bissau is not capable of controlling the international price. Thus, the increase in the price of cashew nuts in Guinea-Bissau's internal market makes the external demand shift to other competing countries, generating internal pressure on the PGB, making it resume the long-term trajectory. This situation is evidenced in the graph of the impulse-response function, which reveals that domestic price shocks have statistically significant effects on external demand only in the first semester.

The same interpretation holds for the exchange rate - Figure (d). In other words, exchange variations have adverse effects on external demand only in the first semester. After this period, the shocks stabilize, i.e., external demand follows its long-term trajectory, regardless of any distortions in exchange markets.

Figure (c) indicates that in the first semester, the external demand variable (XD) reacts negatively to external price shocks (PM). If buyers expect the domestic price to rise, they reduce demand for cashew nuts until the cashew nut markets return to the usual trend. That can be evidenced from the second half of the year onwards when external demand reacts positively to external price shocks. However, after this period, external price shocks dissipated, while demand for cashew nuts followed its long-term trajectory.

It is also possible to verify that shocks to world income (YM), Figure (e), positively affected the demand for exports in the first half of the year. Thereafter, the shocks dissipated, i.e., the demand for exports was no longer affected by variations in foreign income.

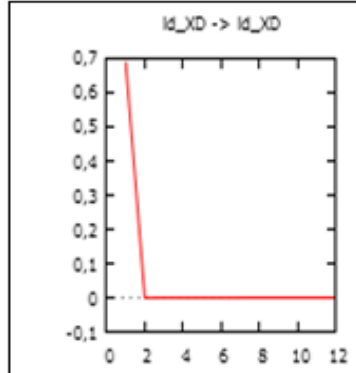

(a)

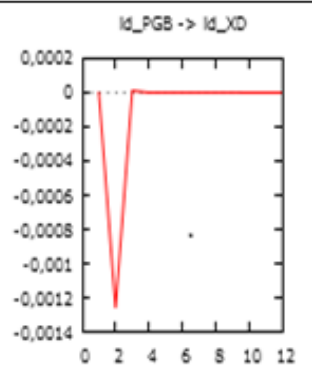

(b)

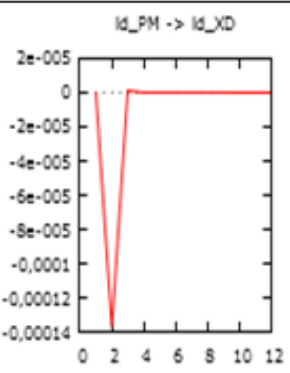

(c)

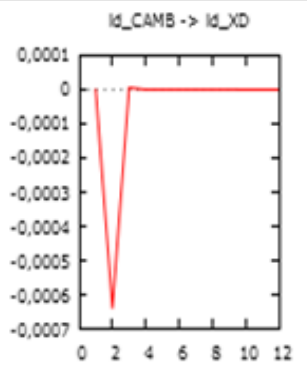

(d)

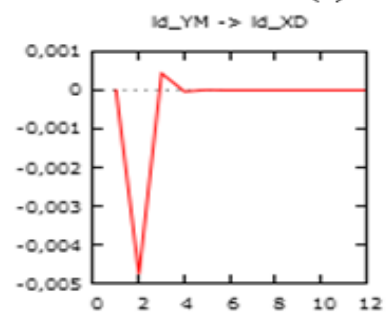

(e)

Figure 1. Response to impulse on cashew nut exports

Source: Own elaboration.

Note. Id: $\log$ differences.

Table 5 presents the variance decomposition estimates over a forecast time horizon of eight semesters, that is, four years. We observe that in the first half of each year, the variance in the forecast error of demand for cashew nut exports is not explained by exchange rate volatility, by variations in external and internal prices, and by 
world income, but by external demand itself. However, the prices, exchange rate, and income explained the variance of the external demand forecast error from the second semester.

Table 5. Decomposition of the forecast error variance of demand for cashew nut exports

\begin{tabular}{lccccc}
\hline Period\# & XD & PGB & PM & CAMB & YM \\
\hline 1 & 100,00 & 0,00 & 0,00 & 0,00 & 0,00 \\
2 & 63,1706 & 0,00 & 0,365 & 0,016 & 36,4484 \\
3 & 58,656 & 0,006 & 1,108 & 0,021 & 40,2090 \\
4 & 58,2582 & 0,022 & 2,149 & 0,024 & 39,5468 \\
5 & 56,5716 & 0,045 & 3,401 & 0,025 & 39,9574 \\
6 & 55,0845 & 0,075 & 4,786 & 0,025 & 40,0295 \\
7 & 53,6045 & 0,108 & 6,233 & 0,025 & 40,0295 \\
8 & 52,1195 & 0,142 & 7,684 & 0,025 & 40,0295 \\
\hline
\end{tabular}

Source: Own elaboration. \#Forecast period or horizon.

The role of domestic price and the exchange rate in explaining the forecast error variance was relatively insignificant. On the other hand, external price and income were statistically significant in explaining the forecast error variance. As a result, we find that said that external income had a considerable percentage in explaining the variance of the forecast error in demand for cashew nut exports from Guinea-Bissau. However, its share remained constant from the sixth semester onwards, signaling that its effect resides in the short and medium-term. In the long run, given the seasonality of the product, external demand does not respond to changes in world income.

In short, the results demonstrate that the demand for cashew nuts is not affected by the variation in the domestic price of this product nor by exchange rate volatility. Over the forecast horizon, it is observed that only changes in world income statistically impact changes in external demand. However, the impacts of external income on demand mainly occur in the medium-term horizon (two years).

\section{Discussion}

Based on this result, which is consistent with conventional economic literature, it is relevant to approach the effect of each of the model's variables, given the peculiarity of the Guinean economy. That said, a possible explanation regarding the non-reaction of external demand, including in the short term, to shocks in the domestic price of cashew nuts lies basically in the fact that the domestic market is of little economic significance. Since the early 1990s, cashew nuts exports have followed its production trend, and, each year, more than $90 \%$ of the quantity produced is exported. In this sense, it is believed that the domestic price is not a vector capable of changing the orientation of Guinean cashew nut production from the foreign to the domestic market.

However, in the medium and long term, changes in the exported quantity have little to do with variations in external prices. Because few countries in the world producing this commodity and production in several countries are destinated to the domestic markets. For example, India is the leading producer, though this countries production is insufficient to meet the domestic demand. Thus, the current price often has a minor role in fluctuations in international demand.

The second explanation may come from the gravitational trade model. Since the distance between countries is negatively related to the flow of trade between them, it is expected that Indian demands commodities from the nearest trading partners the most, so that demand for cashew nuts reflects these aspects more than changes in external prices.

For exchange rate, Guinea-Bissau is part of the West African Economic and Monetary Union (UEMOA). The macroeconomic policies of these countries are harmonized for all member countries so that the current exchange rate, in each period, is the same across countries. Thus, as Guinea-Bissau does not have the autonomy to determine the "optimal" exchange rate to stimulate exports, the contemporary reaction of external demand for Guinean exports would be a function of shocks in other variables, especially the income variable.

However, the effect of income on exports is limited in the short and medium-term. The stability in the parameters of Guinea's foreign trade, in the long run, depends significantly on the current situation in the country, which, after independence, has been faced successive political instability and institutional weaknesses. As a result, although the world income impacts external demand for Guinean cashew nuts in the short and medium-term, in the long-term, the flow of foreign trade in Guinea-Bissau also reflects the prevailing internal circumstances. 
There are no defined international trade policies, and the lack of infrastructure has been the leading cause of the product's damage at the ports. In other words, despite the recent growth in emerging countries that leads to an increase in demand for agricultural commodities, the institutional instabilities in Guinea-Bissau, combined with the lack of internal infrastructure, have been the cause of the low performance of Guinea-Bissau's exports and a concentration of the export grid.

\section{Conclusion}

The objectives of this study were to evaluate whether the demand for export of cashew nuts from Guinea-Bissau reacts to external and internal price shocks, exchange rate, and world income and to analyze whether there was a structural break after the 1998 military conflict.

Based on the VAR (1) results, some hypotheses were confirmed, but others did not. First, it was seen that the demand for export of Guinean cashew nuts is not affected by the variation in the domestic price of this product or by the exchange rate. Contrary to the initial hypothesis, such demand is influenced by variations in external prices and world income. Second, by impulse-response function, it was observed that the prices shocks, exchange rate, and world income impact in the short-run, but when the harvest ended, their effects dissipated. That suggests that despite the positive relationship in the first periods between external demand and changes in world income, the same may not hold in the long periods, given the seasonality of the product.

This result was also evidenced through historical decomposition of the variance of the external demand forecast error that share of world income in explaining the external demand for Guinean cashew nuts has increased in the second semester. Over time, this share remains constant, indicating that the variation in world income influences external demand only in the short and medium-term. Finally, it was also concluded that the demand for exports was affected by the 1990 conflict, which harmed the flow of international trade of cashew nuts, causing a drop in the exports volume.

It suggested that the current trade grid concentration in cashew nuts naturally places it in a situation of external vulnerability since exports depend much more on external factors, such as world income, than on internal ones, such as exchange rate policy. More detailed studies may be required. We found an indication that some internal factors, including civil conflicts, effects cashew nuts export performance. However, we do not know the best institutional design that can change this current situation. That may be a direction for future studies. We suggest applying additional methods, such as computable general equilibrium models and artificial intelligence.

\section{References}

Afzal, M. (2005). Demand and Supply of Export in Pakistan - A Disequilibrium Model. The Labore Journal of Economics, 10(1), 49-64. https://doi.org/10.35536/lje.2005.v10.i1.a4

Arize, A. C. (1987). The supply and demand for imports and export in a simultaneous model. Applied Economics, 19(9), 1233-1247. https://doi.org/10.1080/00036848700000070

Bceao. (2020). Exchange rate database. Retrieved from http://edenpub.bceao.int

Boug, P. E., \& Fagereng, A. (2007). Exchange rate volatility and export performance: A Cointegrated VAR Approach. Statistics Norway, Research Department. Discussion Papers, $n^{\circ} 522$. https://doi.org/10.2139/ssrn.2022923

Bueno, R. L. S. (2008). Econometria de séries temporais. São Paulo: Cengage Learning.

Cavalcanti, M. A. F. H., \& Ribeiro, F. J. (1998). As Exportações Brasileiras no Período 1977/1996: desempenho e determinantes. IPEA Discussion Paper, $n^{\circ} 545$.

Ehrhart, H., \& Guerineau, S. (2012). Commodity price volatility and Tax revenues: Evidence from developing countries. https://doi.org/10.2139/ssrn.2225300

Enders, W. (2010). Applied Econometric Times Series. United States of America: Wiley.

Engle, R. F., \& Granger, C. W. J. (1987). Co-integration and Error Correction: Representation, Estimation and Testing. Econometrica, 55(2), 251-228. https://doi.org/10.2307/1913236

FAO (Food and Agriculture Organization of the United Nations). (2015). Database. Retrieved from http://faostat.fao.org/site/342/default.aspx

Goldstein, M., \& Khan, M. S. (1978). The supply and demand for exports: a simultaneous approach. The Review of Economics and Statistics, 60(2), 275-286. https://doi.org/10.2307/1924981

Guiné-Bissau. (2010). Beyond Cashew Nuts: Diversification through trad. Retrieved from. 
http://wwwwds.worldbank.org/external/default/WDSContentServer/WDSP/IB/2011/02/10/000333038_201 10210233340/Rendered/PDF/595620ESW0PORT1Main0Report01PUBLIC1.pdf

Hamilton, J. G. (1994). Time Series Analysis. Princinton UNiversity Press. https://doi.org/10.1515/9780691218632

Imai, K., \& Weinstein, J. (2000). Measuring the Economic Impact of Civil War. CID Working Paper, $n^{\circ} 51$.

Jamal, H. (2008). Traditional Export Demand Relation: A Cointegration and Parameter Constancy Analysis. International. Journal of Applied Economics and Quantitative Studies, 5(2), 41-65. https://doi.org/10.1108/01443580110400414

Konandreas, P., Bushnell, P., \& Green, R. (1978). Estimation of Export Demand Functions For U.S. Wheat. Western Journal of Agriculture Economics, 39-50. https://doi.org/10.22004/ag.econ.32402

Monte, E. Z. (2012). Exportações de café do Espírito Santo Aplicação da metodologia VAR. Revista de Política Agrícola, 4, 106-119. Retrieved from https://seer.sede.embrapa.br/index.php/RPA/article/view/268/227

Morettin, P. A., \& Toloi, C. M. (1985). Previsão de séries temporais. São Paulo: Atual.

Murteira, B. J. F., Müller, D. A., \& Turkman, K. F. (1993). Análise de sucessões cronológicas. Lisboa: McGrauw Hill.

Orcutt, G. H. (1950). Measurement of Price Elasticities in International Trade. The Review of Economics and Statistics, 32(2), 117-132. https://doi.org/10.2307/1927649

Pandey, R. (2013). Trade Elasticities and the Marshal Lerner Condition for India. Global Journal of Management and Business $\quad$ Studies, 3(4), 423-428. Retrieved from https://www.ripublication.com/gjmbs_spl/gjmbsv3n4_13.pdf

Reimer, J. J., Zheng, X., \& Gehlhar, M. J. (2012). Export Demand Elasticity Estimation for Major U.S. Crops. Journal of Agricultural and Applied Economics, 44(4), 501-515. https://doi.org/10.1017/S107407080002407X

Riaz, F., Afzal, M., \& Haider, J. (2011). Estimation of import and export demand functions using bilateral trade data: The case of Pakistan. Business and Economic Horizons, 6(3), 40-53. https://doi.org/10.15208/beh.2011.17

Shigeyuki, H., \& Yoichi, M. (2009). Empirical Analysis of Export Demand Behavior of LDCs: Panel Cointegration Approach. Munich Personal RePEc Archive, n.17316.

Silva, M. V. S. S., \& Bacchi, M. R. P. B. (2005). Condicionantes das exportações brasileiras de açúcar bruto. Agricultura em São Paulo, São Paulo, 52(2), 99-110. Retrieved from https://www.scielo.br/j/resr/a/s4sT9rmGcrHyTRsBwBWGYrv/?lang=pt\&format=pdf

Sims, C. A. (1980). Macroeconomics and Reality. Econometrica, 48(01), 01-48. https://doi.org/10.2307/1912017

UNCTAD. (2012). Commodities and Development Report. Retrieved from http://unctad.org/en/PublicationsLibrary/suc2011d9_en.pdf

United Nations Comtrade. (2015). Bilateral trade flow data. Retrieved from http://comtrade.un.org/data/

VIA, A. (2011). Estimating Price Elasticities in International Trade: Is the Empirical Evidence Beyond Proof? Retrieved from http://www.etsg.org/ETSG2011/Papers/Via.pdf

Watson. M. W. (1994). Vector Autoregressions and Cointegration. Chicago: Handbook of Econometrics. https://doi.org/10.1016/S1573-4412(05)80016-9

World Bank. (2020). World Devevopment Indicators. Retrieved from http://data.worldbank.org/

\section{Copyrights}

Copyright for this article is retained by the author(s), with first publication rights granted to the journal.

This is an open-access article distributed under the terms and conditions of the Creative Commons Attribution license (http://creativecommons.org/licenses/by/4.0/). 